\title{
Clinical Pharmacokinetic and Pharmacodynamic Profile of Riociguat
}

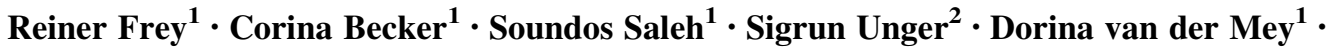 \\ Wolfgang Mück ${ }^{1}$
}

Published online: 30 October 2017

(c) The Author(s) 2017. This article is an open access publication

\begin{abstract}
Oral riociguat is a soluble guanylate cyclase (sGC) stimulator that targets the nitric oxide (NO)-sGC-cyclic guanosine monophosphate pathway with a dual mode of action: directly by stimulating $\mathrm{sGC}$, and indirectly by increasing the sensitivity of sGC to NO. It is rapidly absorbed, displays almost complete bioavailability (94.3\%), and can be taken with or without food and as crushed or whole tablets. Riociguat exposure shows pronounced interindividual (60\%) and low intraindividual (30\%) variability in patients with pulmonary arterial hypertension (PAH) or chronic thromboembolic pulmonary hypertension (CTEPH), and is therefore administered using an individual dose-adjustment scheme at treatment initiation. The half-life of riociguat is approximately $12 \mathrm{~h}$ in patients and approximately $7 \mathrm{~h}$ in healthy individuals. Riociguat and its metabolites are excreted via both renal $(33-45 \%)$ and biliary routes (48-59\%), and dose adjustment should be performed with particular care in patients with moderate hepatic impairment or mild to severe renal impairment (no data exist for patients with severe hepatic impairment). The pharmacodynamic effects of riociguat reflect the action of a vasodilatory agent, and the hemodynamic response to riociguat correlated with riociguat exposure in patients with PAH or CTEPH in phase III population pharmacokinetic/pharmacodynamic analyses. Riociguat has a low risk of clinically relevant drug interactions due to its clearance by multiple cytochrome P450 (CYP) enzymes and its lack of effect on major CYP isoforms
\end{abstract}

Electronic supplementary material The online version of this article (doi:10.1007/s40262-017-0604-7) contains supplementary material, which is available to authorized users.

Reiner Frey

reiner.frey@bayer.com

1 Clinical Pharmacology, Bayer AG, Wuppertal, Germany

2 Global Biostatistics, Bayer AG, Wuppertal, Germany and transporter proteins at therapeutic levels. Riociguat has been approved for the treatment of PAH and CTEPH that is inoperable or persistent/recurrent after surgical treatment.

\section{Key Points}

The pharmacokinetics of oral riociguat are characterized by rapid absorption, almost complete bioavailability, and dose-proportional exposure, which correlates with its pharmacodynamic effects. Riociguat exposure varies substantially between patients; this has been addressed by use of an individual dose-adjustment scheme at treatment initiation, which has been proven to be safe and efficacious in phase III studies in patients with pulmonary arterial hypertension and chronic thromboembolic pulmonary hypertension, and appears to be practical and straightforward in clinical practice.

Most intrinsic and extrinsic factors that influence riociguat pharmacokinetics or pharmacodynamics do not warrant further dose adjustment beyond the individual dose-adjustment scheme; however, particular care should be exercised during individual dose adjustment in elderly patients and those with moderate hepatic impairment or mild to severe renal impairment. Concomitant use of riociguat with strong multipathway cytochrome $\mathrm{P} 450$ and P-glycoprotein/breast cancer resistance protein inhibitors should be avoided or approached with caution because of the risk of hypotension; a reduced starting dose of $0.5 \mathrm{mg}$ three times daily might be considered. Smoking decreases riociguat exposure, and dose adjustments may be necessary in patients who start or stop smoking during treatment. 


\section{Introduction}

Pulmonary hypertension $(\mathrm{PH})$ is a progressive disorder, defined by a mean pulmonary arterial pressure $\geq 25 \mathrm{mmHg}$ at rest measured by right heart catheterization, which can be severely life-limiting for patients [1]. PH is characterized by pulmonary vasoconstriction, vascular remodeling, thrombosis, and inflammation [2], and has been classified into five groups based on the cause, pathologic findings, and hemodynamic characteristics [3]. Two of these PH groups are pulmonary arterial hypertension (PAH; Group 1) and chronic thromboembolic PH (CTEPH; Group 4). Nitric oxide (NO), endothelin, and prostacyclin signaling pathways have been implicated in the pathophysiology of PAH [4]. NO plays a key role in the regulation of pulmonary vascular tone: endogenous NO binds to the enzyme soluble guanylate cyclase (sGC) in vascular smooth muscle cells, stimulating sGC to produce the secondary messenger cyclic guanosine monophosphate (cGMP), which in turn activates cGMP-dependent protein kinase to reduce the intracellular calcium concentration and prevent smooth muscle contraction [5]. Reduced levels of endogenous NO have been found in PH [6], and altered NO-sGC-cGMP signaling has been implicated in the pathophysiology of $\mathrm{PH}$, including vasoconstriction, inflammation, and pulmonary vascular remodeling [5].

The various treatment options for $\mathrm{PH}$ have been described in detail in the 2015 European Respiratory Society/European Society of Cardiology (ERS/ESC) treatment guidelines [1]. Riociguat is an oral medication that targets the NO-sGC-cGMP pathway [7], and its benefits in the management of several $\mathrm{PH}$ groups have been explored [5, 8-11]. In particular, pivotal phase III, randomized, placebo-controlled trials of riociguat-the PATENT-1 and CHEST-1 studies-were performed in patients with PAH $(n=443)$ and CTEPH $(n=261)$, respectively [12, 13]. Patients in PATENT-1 and CHEST-1 received placebo or riociguat individually dose adjusted up to $2.5 \mathrm{mg}$ three times daily according to systolic blood pressure (SBP) and signs/symptoms of hypotension (Fig. S1 in the Online Resource) [12-15]. In both studies, riociguat was generally well tolerated and significantly improved a range of clinical endpoints, including 6-min walking distance (6MWD), World Health Organization (WHO) functional class, and levels of $\mathrm{N}$-terminal prohormone of brain natriuretic peptide (NT-proBNP), compared with placebo [12, 13]. These improvements were maintained after 2 years of riociguat treatment in the open-label extension studies-PATENT2 and CHEST-2-and no new safety signals were identified $[16,17]$.
Based on these results, riociguat has been approved in Europe and the US for the treatment of adults with PAH and adults with CTEPH that is inoperable or persistent/ recurrent after surgical treatment $[18,19]$. Contraindications are described in the product label $[18,19]$.

The role of riociguat in the management of PAH and CTEPH is addressed in PH treatment guidelines [1] and a recent review [5], while the clinical use, efficacy, and tolerability of riociguat are described elsewhere $[12,13,15-17,19-21]$. In this review, we focus on the pharmacokinetic/pharmacodynamic profile of riociguat, including drug-drug interaction data, population pharmacokinetic/pharmacodynamic relationships in patients with PAH or CTEPH, and the implications of these results for clinical use.

\section{Physiochemical Properties and Preclinical Pharmacology}

\subsection{Physiochemical Properties}

Riociguat (methyl 4,6-diamino-2-[1-(2-fluorobenzyl)-1Hpyrazolo [3,4-b]pyridin-3-yl]-5-pyrimidinyl(methyl)carbamate) has a molecular weight of $422.42 \mathrm{~g} / \mathrm{mol}$ [18]. Its chemical structure is shown in Fig. 1. Riociguat is highly soluble in aqueous acidic medium but poorly soluble in pure water at neutral $\mathrm{pH}[15,18]$. In phase I clinical studies, riociguat was detected in plasma $15 \mathrm{~min}$ after administration of an immediate-release (IR) tablet, suggesting it is highly permeable. It is therefore designated as a Class II (low solubility, high permeability) drug according to the Biopharmaceutics Classification System [22].

\subsection{Mode of Action and Preclinical Pharmacology}

Riociguat has a dual mode of action: it directly stimulates sGC independently of NO, and sensitizes sGC to endogenous NO by stabilizing NO-sGC binding [7, 23]. Further details regarding the mechanisms by which $\mathrm{NO}$ and sGC stimulators affect sGC activity can be found elsewhere [5, 6, 24, 25]. In preclinical studies, the activity of recombinant sGC was increased by up to 73 -fold by riociguat alone, and by up to 112 -fold by riociguat in combination with an NO-releasing drug [23]. Riociguat promoted arterial relaxation in isolated saphenous artery rings from normal and nitrate-resistant rabbits [26], and showed beneficial effects in rodent models of systemic hypertension, $\mathrm{PAH}$, and $\mathrm{PH}$ due to left heart disease, chronic obstructive pulmonary disease, and pulmonary fibrosis (see Table S1 in the Online Resource) [5]. 


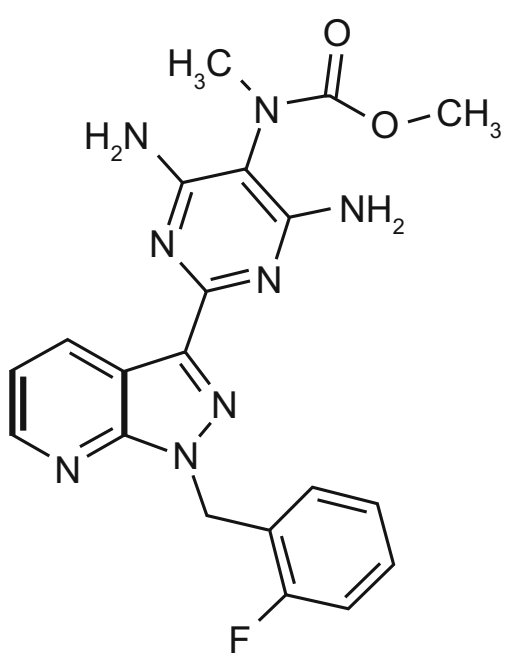

Fig. 1 Chemical structure of riociguat (methyl 4,6-diamino-2-[1-(2fluorobenzyl)-1H-pyrazolo [3,4-b]pyridin-3-yl]-5-pyrimidinyl(methyl) carbamate)

\section{Pharmacokinetic Properties}

\subsection{Absorption}

Riociguat is rapidly absorbed after oral administration, the maximum concentration in plasma $\left(C_{\max }\right)$ being reached after approximately $0.5-1.5 \mathrm{~h}$ with riociguat $0.25-5.0 \mathrm{mg}$ administered as an oral solution [27], or after approximately $0.8-1.0 \mathrm{~h}$ with riociguat $0.5-2.5 \mathrm{mg}$ administered as an IR oral tablet [28] in healthy male volunteers. Systemic exposure to riociguat is dose proportional [27, 29]. Riociguat exposure shows moderate to high interindividual variability in healthy individuals [geometric mean coefficient of variation of $\sim 100 \%$ for area under the plasma concentration-time curve from time zero to infinity $\left(\mathrm{AUC}_{\infty}\right)$ and $\sim 45 \%$ for $C_{\max }$ ], whereas intraindividual variability is low (geometric coefficient of variation of $<20 \%$ for $\mathrm{AUC}_{\infty}$ and $C_{\max }$ ) [28].

The mean $\mathrm{AUC}_{\infty}$ is similar for riociguat $1.0 \mathrm{mg}$ administered as an oral IR tablet or as an intravenous infusion over $60 \mathrm{~min}(244 \mathrm{vs.} 259 \mu \mathrm{g} \cdot \mathrm{h} / \mathrm{L}$, respectively) and the absolute bioavailability is $94.3 \%$ [28], indicating unrestrained absorption and a little presystemic first-pass extraction (Fig. 2). There are no relevant differences in bioavailability between oral riociguat $2.5 \mathrm{mg}$ administered as a solution or as an IR tablet [27]. Riociguat bioavailability is also similar between $1.0 \mathrm{mg}$ IR tablets and $0.15,0.3$, and $2.4 \mathrm{mg}$ oral suspensions (AUC/dose estimate ratio 93.6-104.3\%), and between whole $2.5 \mathrm{mg}$ IR tablets and crushed $2.5 \mathrm{mg}$ IR tablets suspended in water (AUC estimate ratio: $103.3 \%$ ) or applesauce (AUC estimate ratio 98.5\%) [30].

Food has only a minor impact on the AUC of riociguat (Table 1). A high-fat and high-calorie breakfast was shown to delay absorption of riociguat administered as a $2.5 \mathrm{mg}$ IR tablet (likely by delaying gastric emptying): the median time to reach $C_{\max }$ was $4 \mathrm{~h}$ in the fed state compared with $1 \mathrm{~h}$ in the fasted state. However, the breakfast had only a minimal effect on the extent of absorption (fed/fasted ratio for AUC 88.3\%) [28]. In the pivotal phase III clinical trials, riociguat tablets were administered irrespective of food intake [15].

\subsection{Distribution}

Riociguat is mainly distributed into plasma, with a blood:plasma partition coefficient of approximately 0.7 . Riociguat plasma protein binding is approximately $95 \%$ in vitro and fully reversible; serum albumin and $\alpha-1$ acid glycoprotein are the main binding components $[15,18,19]$. The volume of distribution of riociguat at steady state after intravenous administration is $30.1 \mathrm{~L}$, indicating a low affinity for tissues (Fig. 2) [15, 28]. Based on studies in rats, riociguat shows low penetration across the bloodbrain barrier and moderate penetration across the placental barrier. In lactating rats administered radiolabeled riociguat, an estimated $2.2 \%$ of the dose was excreted in milk within $32 \mathrm{~h} \mathrm{[15].}$

\subsection{Metabolism and Elimination}

The main biotransformation pathway for riociguat is $\mathrm{N}$ demethylation catalyzed by cytochrome P450 (CYP) 1A1, CYP3A4, CYP3A5, CYP2C8, and CYP2J2 [15, 18, 19] (Fig. 2). CYP1A1 is primarily responsible for the formation of the major active metabolite M1, which has onetenth to one-third of the biological activity of riociguat $[15,19]$. M1 is further metabolized by uridine diphosphate glucuronosyltransferase (UGT) 1A1 and UGT1A9 to produce the inactive $N$-glucuronide M4. Of note, CYP1A1 is induced by polycyclic aromatic hydrocarbons such as those present in cigarette smoke, leading to an increased rate of riociguat metabolism in smokers compared with nonsmokers [15, 18, 19, 29, 31].

Total riociguat (unchanged riociguat and its metabolites) is excreted via both renal (33-45\%) and biliary/fecal (48-59\%) routes. Overall, 27 to $\sim 71 \%$ of the dose is eliminated by oxidative biotransformation (as M1, M3, and M4), $9-44 \%$ is excreted unchanged in feces $(15-43 \%$ as M1), and $4-19 \%$ is excreted unchanged in urine via glomerular filtration (Fig. 2) [15]. Riociguat is a substrate of the transporter proteins P-glycoprotein (P-gp) and breast cancer resistance protein (BCRP] [19]. It is a low-clearance drug, with an average systemic clearance of $\sim 3.4 \mathrm{~L} / \mathrm{h}$ in healthy non-smokers $(6.0 \mathrm{~L} / \mathrm{h}$ in smokers) [28]. The average terminal half-life of a single dose of riociguat $1 \mathrm{mg}$ in 


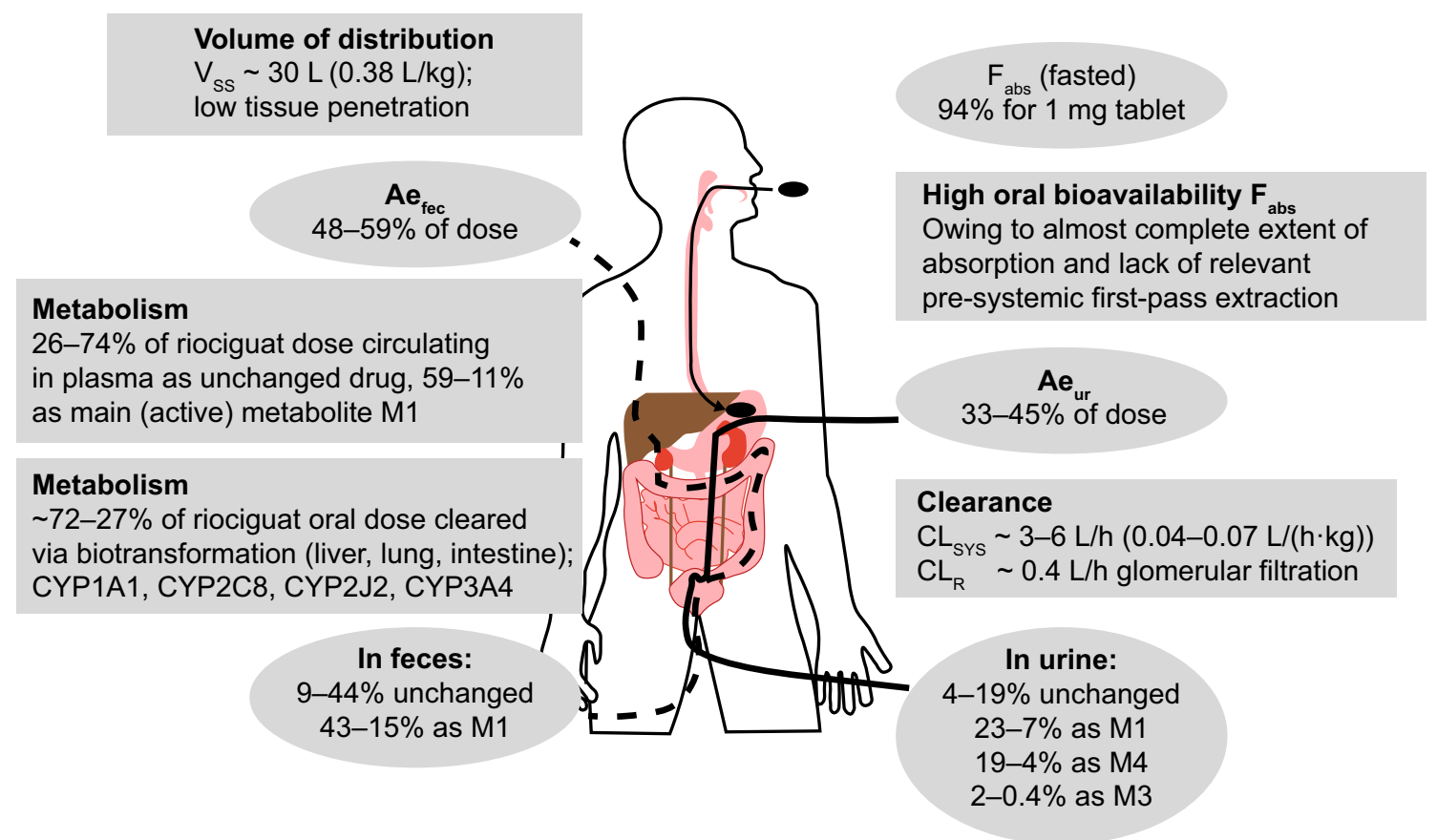

Fig. 2 Summary of riociguat mass-balance, excretion-pattern, distribution, and clearance properties in humans. All numbers are approximate; sum of percentages is $90-95 \%$, which is the recovery of radiolabel in the human mass-balance study $(n=4)$. Percentages separated by dashes indicate minimum-maximum observed values in the mass-balance study. $A e_{u r}$ amount excreted into urine, $A e_{f e c}$

healthy non-smokers is $8.2 \mathrm{~h}$, decreasing to $4.5 \mathrm{~h}$ in smokers [28].

\section{Pharmacokinetic Properties in Special Populations}

\subsection{Smoking}

CYP1A1 is induced by polycyclic aromatic hydrocarbons such as those present in cigarette smoke, leading to an increased rate of riociguat metabolism in smokers versus non-smokers [15, 18, 19, 29, 31]. Consequently, smoking induces metabolism of riociguat to $\mathrm{M} 1$, leading to reduced riociguat exposure in smokers (Table 1), while metabolite M1 exposure is increased. In healthy Caucasian volunteers receiving riociguat $2.5 \mathrm{mg}$ three times daily, mean riociguat AUC at steady state was $692.8 \mu \mathrm{g} \cdot \mathrm{h} / \mathrm{L}$ in nonsmokers and $215.0 \mu \mathrm{g} \cdot \mathrm{h} / \mathrm{L}$ in smokers (a reduction of $-69 \%$ ), whereas mean M1 AUC at steady state was $379.5 \mu \mathrm{g} \cdot \mathrm{h} / \mathrm{L}$ in non-smokers and $633.5 \mu \mathrm{g} \cdot \mathrm{h} / \mathrm{L}$ in smokers (an increase of $+67 \%$ ) [31]. Mean riociguat $C_{\max }$ at steady state was $116.5 \mu \mathrm{g} / \mathrm{L}$ in non-smokers and $59.6 \mu \mathrm{g} / \mathrm{L}$ in smokers (a reduction of $-49 \%$ ), and mean M1 $C_{\max }$ was amount excreted into bile/feces, $C L_{s y s}$ systemic (plasma) clearance, $C L_{R}$ renal clearance (via glomerular filtration), $C Y P$ cytochrome P450, $F_{a b s}$ absolute bioavailability, $M 1, M 3$, and $M 4$ metabolites M1 (BAY 60-4552), M3, and M4, $V_{s s}$ volume of distribution at steady state

$56.3 \mu \mathrm{g} / \mathrm{L}$ in non-smokers and $95.1 \mu \mathrm{g} / \mathrm{L}$ in smokers (an increase of $+69 \%$ ) [31]. A study in healthy Chinese volunteers demonstrated a reduction by at least $-60 \%$ in riociguat exposure in smokers compared with non-smokers [29]. $C_{\max }$ divided by dose per kilogram body weight $\left(C_{\max , \text { norm }}\right)$ was decreased in smokers by $-20 \%$ after a single dose and $-44 \%$ at steady state after multiple dosing [29]. Smoking also led to reduced riociguat exposure in individuals with renal or hepatic impairment (described further in Sect. 4.3) [32, 33].

\subsection{Ethnicity}

Japanese people tend to have higher riociguat exposure than other ethnic groups (Table 1), although this difference is less pronounced after normalization for body weight. African American and Chinese individuals have riociguat exposures after body-weight normalization within the range of interindividual variability seen for Caucasians [15]. In healthy Chinese volunteers, riociguat had nearly dose-proportional pharmacokinetics with only slight accumulation at steady state, with high interindividual variability as seen previously in Caucasians [29]. 
Table 1 Impact of intrinsic and extrinsic factors on riociguat exposure

\begin{tabular}{|c|c|c|}
\hline Factors & $\begin{array}{l}\text { Effect on riociguat } \\
\text { concentration }\end{array}$ & Comments/recommendations \\
\hline \multicolumn{3}{|l|}{ Intrinsic factors } \\
\hline $\begin{array}{l}\text { Renal impairment } \\
\text { [33] }\end{array}$ & Increase & $\begin{array}{l}\text { Riociguat exposure }\left(\mathrm{AUC}_{\text {norm }}\right) \text { was increased in individuals with renal impairment (estimated } \\
\text { ratio of exposure vs. healthy controls: } 143,204 \text {, and } 144 \% \text { in those with mild, moderate, and } \\
\text { severe renal impairment, respectively). Dose adjustment should be performed with particular } \\
\text { care. No data are available for patients with creatinine clearance }<15 \mathrm{~mL} / \mathrm{min} \text { or on dialysis, } \\
\text { therefore riociguat is not recommended in these patients }\end{array}$ \\
\hline $\begin{array}{l}\text { Hepatic impairment } \\
{[32]}\end{array}$ & Increase & $\begin{array}{l}\text { Riociguat exposure }\left(\mathrm{AUC}_{\mathrm{n} o r m}\right) \text { was significantly increased in individuals with moderate } \\
\text { (Child-Pugh B) but not mild (Child-Pugh A) hepatic impairment (estimated ratio of } \\
\text { exposure vs. healthy controls: } 153 \text { and } 106 \% \text {, respectively). Dose adjustment should be } \\
\text { performed with particular care in patients with moderate hepatic impairment. There is no } \\
\text { experience in patients with severe hepatic impairment (Child-Pugh C), and riociguat should } \\
\text { not be used in these patients }\end{array}$ \\
\hline $\begin{array}{l}\text { Age (elderly vs. } \\
\text { young) [32] }\end{array}$ & Increase & $\begin{array}{l}\text { Riociguat exposure showed a non-significant increase in individuals aged } 64.5-80 \text { years } \\
\text { compared with individuals aged } 18-45 \text { years }\left(\mathrm{AUC}_{\text {norm }}:+28 \% ; C_{\text {max,norm }}: 5 \%\right) \text {. Further } \\
\text { dose adjustment beyond the individual dose-adjustment scheme is not necessary but } \\
\text { particular care should be exercised in elderly patients }\end{array}$ \\
\hline Sex [32] & $\begin{array}{r}\text { No relevant } \\
\text { difference }\end{array}$ & $\begin{array}{l}\text { Riociguat exposure was similar in both women and men [AUC: }+9 \% ; \mathrm{AUC}_{\text {norm }}:-3 \% \\
\text { (women vs. men)] }\end{array}$ \\
\hline $\begin{array}{l}\text { Japanese (vs. } \\
\text { Caucasian) ethnicity }\end{array}$ & $\begin{array}{r}\text { No relevant } \\
\text { difference }\end{array}$ & $\begin{array}{l}\text { Body weight-normalized AUC was slightly higher in Japanese individuals vs. Caucasian } \\
\text { individuals }(+12 \%) \text {. No dose adjustment beyond the individual dose-adjustment scheme is } \\
\text { necessary }\end{array}$ \\
\hline \multicolumn{3}{|l|}{ Extrinsic factors } \\
\hline Food & $\begin{array}{r}\text { No relevant } \\
\text { difference }\end{array}$ & $\begin{array}{l}\text { AUC was slightly reduced in the fed vs. fasted state }(-11.7 \%) \text {; this difference is not clinically } \\
\text { relevant and riociguat can be taken with or without food. However, as a precautionary } \\
\text { measure, switches between fed and fasted riociguat intake are not recommended for patients } \\
\text { prone to hypotension }\end{array}$ \\
\hline Smoking $[29,31,33]$ & Decrease & $\begin{array}{l}\text { Riociguat exposure is reduced by } 50-60 \% \text { in smokers compared with non-smokers. Dose } \\
\text { adjustments may be necessary in patients who start or stop smoking during riociguat } \\
\text { treatment, and patients who smoke may require riociguat dosages higher than } 2.5 \mathrm{mg} \text { tid if } \\
\text { tolerated }\end{array}$ \\
\hline \multicolumn{3}{|c|}{ Drugs affecting gastric $\mathrm{pH}$} \\
\hline Antacid $\left(\right.$ Maalox $\left.^{\circledR}\right)$ & Decrease & $\begin{array}{l}\text { Coadministration of aluminum hydroxide/magnesium hydroxide }\left(\text { Maalox }{ }^{\circledR} ; 10 \mathrm{~mL}\right) \text { reduced } \\
\text { riociguat } \mathrm{AUC}_{\infty} \text { by }-34 \% \text {. Antacids should be taken at least } 2 \mathrm{~h} \text { before or } 1 \mathrm{~h} \text { after } \\
\text { riociguat. Further riociguat dose adjustment beyond the individual dose-adjustment } \\
\text { scheme is not necessary }\end{array}$ \\
\hline Omeprazole & $\begin{array}{r}\text { No relevant } \\
\text { difference }\end{array}$ & $\begin{array}{l}\text { Pre- and coadministration of omeprazole }(40 \mathrm{mg} \mathrm{qd}) \text { reduced riociguat } \mathrm{AUC}_{\infty} \text { by }-26 \% \text {. } \\
\text { Further riociguat dose adjustment beyond the individual dose-adjustment scheme is not } \\
\text { necessary }\end{array}$ \\
\hline Ranitidine & $\begin{array}{r}\text { No relevant } \\
\text { difference }\end{array}$ & $\begin{array}{l}\text { Coadministration of ranitidine ( } 150 \mathrm{mg} \mathrm{qd}) \text { reduced riociguat AUC by approximately }-10 \% \text {. } \\
\text { Further riociguat dose adjustment beyond the individual dose-adjustment scheme is not } \\
\text { necessary }\end{array}$ \\
\hline Ketoconazole [31] & Increase & $\begin{array}{l}\text { Pre- and coadministration of ketoconazole }(400 \mathrm{mg} \mathrm{qd}) \text { increased riociguat } \mathrm{AUC}_{\infty} \text { by } \\
\text { approximately }+150 \%\left(C_{\max } \text { increased by approximately }+46 \%\right) \text {. Concomitant use of } \\
\text { riociguat with strong multipathway CYP and P-gp/BCRP inhibitors, such as ketoconazole } \\
\text { and HIV protease inhibitors, should be approached with caution }\end{array}$ \\
\hline Clarithromycin [31] & $\begin{array}{r}\text { No relevant } \\
\text { difference }\end{array}$ & $\begin{array}{l}\text { Pre- and coadministration of clarithromycin }(500 \mathrm{mg} \text { bid }) \text { increased riociguat } \mathrm{AUC}_{\infty} \text { by } \\
+41 \%\left(C_{\max } \text { was unchanged). Further dose adjustment beyond the individual dose- }\right. \\
\text { adjustment scheme is not necessary for patients receiving comedication inhibiting either the } \\
\text { CYP3A4 pathway (e.g. clarithromycin) or the P-gp/BCRP-mediated excretion of riociguat }\end{array}$ \\
\hline $\begin{array}{l}\text { Levonorgestrel- } \\
\text { ethinylestradiol }\end{array}$ & $\begin{array}{r}\text { No relevant } \\
\text { difference }\end{array}$ & $\begin{array}{l}\text { Coadministration of levonorgestrel-ethinylestradiol did not alter riociguat exposure. Riociguat } \\
\text { pre- and coadministration did not alter the AUC of ethinylestradiol and levonorgestrel } \\
\text { (estimated ratios of exposure: } 102 \text { and } 100 \% \text {, respectively). Further riociguat dose } \\
\text { adjustment beyond the individual dose-adjustment scheme is not necessary }\end{array}$ \\
\hline Bosentan [36] & $\begin{array}{r}\text { No relevant } \\
\text { difference }\end{array}$ & $\begin{array}{l}\text { Coadministration of bosentan in patients with PAH and CTEPH decreased riociguat AUC by } \\
-27 \% \text {. This small effect does not require riociguat dose adjustment beyond the individual } \\
\text { dose-adjustment scheme }\end{array}$ \\
\hline
\end{tabular}


Table 1 continued

\begin{tabular}{|c|c|c|}
\hline Factors & $\begin{array}{l}\text { Effect on riociguat } \\
\text { concentration }\end{array}$ & Comments/recommendations \\
\hline $\begin{array}{l}\text { Nitrates/nitric oxide } \\
\text { donors }\end{array}$ & $\begin{array}{l}\text { Pharmacodynamic } \\
\text { interaction }\end{array}$ & $\begin{array}{l}\text { Riociguat }(2.5 \mathrm{mg}) \text { potentiated the blood pressure-lowering effect of sublingual nitroglycerin } \\
(0.4 \mathrm{mg}) \text {. Syncope was reported in some patients. Coadministration of riociguat with nitrates } \\
\text { or nitric oxide donors is therefore contraindicated }\end{array}$ \\
\hline Sildenafil [43] & $\begin{array}{l}\text { Pharmacodynamic } \\
\text { interaction }\end{array}$ & $\begin{array}{l}\text { Addition of riociguat to sildenafil therapy resulted in additive hemodynamic effects and } \\
\text { potentially unfavorable safety signals with no evidence for a positive benefit/risk ratio. } \\
\text { Coadministration of riociguat with phosphodiesterase- } 5 \text { inhibitors is therefore } \\
\text { contraindicated }\end{array}$ \\
\hline Warfarin [48] & $\begin{array}{r}\text { No relevant } \\
\text { difference }\end{array}$ & $\begin{array}{l}\text { Pre- and coadministration of riociguat } 2.5 \mathrm{mg} \text { tid had no relevant effect on warfarin } \mathrm{AUC}_{\infty} \\
\text { (estimated ratio } 101 \% \text { ) or pharmacodynamics (prothrombin time and percentage activities of } \\
\text { factor VII, factor II, and factor X). Coadministration of warfarin }(25 \mathrm{mg} \text { ) did not } \\
\text { significantly alter riociguat } \mathrm{AUC}_{\tau, \mathrm{ss}} \text { (estimated ratio } 96 \% \text { ). Further riociguat dose adjustment } \\
\text { beyond the individual dose-adjustment scheme is not necessary }\end{array}$ \\
\hline $\begin{array}{l}\text { Acetylsalicylic acid } \\
\text { [49] }\end{array}$ & $\begin{array}{r}\text { No relevant } \\
\text { difference }\end{array}$ & $\begin{array}{l}\text { Pre- and coadministration of acetylsalicylic acid ( } 500 \mathrm{mg} \text { qd) did not significantly alter } \\
\left.\text { riociguat } \mathrm{AUC}_{\infty} \text { (estimated ratio } 96 \%\right) \text {. Riociguat did not potentiate the effect of } \\
\text { acetylsalicylic acid on bleeding time or platelet aggregation. Further riociguat dose } \\
\text { adjustment beyond the individual dose-adjustment scheme is not necessary }\end{array}$ \\
\hline
\end{tabular}

$\overline{A U C}$ area under the plasma concentration-time curve, $A U C_{\infty}$ AUC from time zero to infinity, $A U C_{n o r m}$ AUC divided by dose per kilogram body weight, $A U C_{\tau, s s}$ AUC for the dose interval $\tau$ at steady state, $B C R P$ breast cancer resistance protein, bid twice daily, $C_{\text {max }}$ maximum concentration in plasma, $C_{\max , \text { norm }} C_{\max }$ divided by dose per kilogram body weight, $C T E P H$ chronic thromboembolic pulmonary hypertension, $C Y P$ cytochrome P450, HIV human immunodeficiency virus, $P A H$ pulmonary arterial hypertension, $P$ - $g p$ P-glycoprotein, $q d$ once daily, $t i d$ three times daily

\subsection{Comorbidities}

\subsubsection{Renal Impairment}

Individuals with renal impairment were found to have reduced apparent oral clearance $(\mathrm{CL} / \mathrm{F})$ of riociguat compared with healthy controls after administration of a single dose, but no direct relationship was observed with the severity of impairment $(4.07 \mathrm{~L} / \mathrm{h}$ in healthy controls vs. 2.67, 2.00, and $2.61 \mathrm{~L} / \mathrm{h}$ in individuals with mild, moderate, and severe renal impairment, respectively) [33]. However, renal clearance of riociguat progressively decreased with increasing renal impairment $(-32,-67$, and $-82 \%$ reductions for mild, moderate, and severe renal impairment, respectively, vs. healthy controls), and showed a monotonically increasing relationship with creatinine clearance $(\mathrm{CrCl}$; calculated using the Cockcroft-Gault formula, as in all pharmacokinetic/pharmacodynamic studies). Both CL/F and renal clearance of M1 decreased progressively with increasing renal impairment [33].

Riociguat exposure $\left(\mathrm{AUC}_{\text {norm }}\right)$ was increased in the presence of renal impairment but showed no consistent pattern with increasing severity of renal impairment: the estimated ratio of exposure versus healthy controls was 143,204 , and $144 \%$ in those with mild, moderate, and severe renal impairment, respectively (Table 1) [33]. Riociguat and M1 exposures were highly variable and the ranges overlapped with those observed in healthy controls. Non-smokers had greater exposure to riociguat than the total study populations of smokers and non-smokers combined, irrespective of renal function (Table 2) [33].

In a mechanistic population pharmacokinetic analysis of data from studies in individuals with hepatic or renal impairment, riociguat pharmacokinetics were well described by a two-compartment model [30]. Total riociguat clearance occurred predominantly via metabolism to M1. Renal impairment reduced riociguat and M1 clearance but had only moderate effects on drug exposure in this model because of the contribution of biliary/fecal excretion to the total clearance of riociguat [30].

\subsubsection{Hepatic Impairment}

Compared with healthy controls, single-dose riociguat exposure was significantly increased by moderate hepatic impairment (Child-Pugh B; estimated ratio 153\%) but not by mild hepatic impairment (Child-Pugh A; estimated ratio $106 \%$ ) (Table 1) [32]. The half-life of M1 was prolonged by approximately +24 and $+43 \%$ in individuals with mild and moderate hepatic impairment, respectively, compared with healthy controls. The antagonistic effects of reduced formation and elimination of metabolite M1 in individuals with hepatic impairment led to M1 exposures that were broadly similar to those observed in healthy controls [32]. Non-smokers with hepatic impairment had greater exposure to riociguat than the total study populations (smokers and non-smokers combined) with hepatic impairment (Table 2) [32]. 
Table 2 Riociguat exposure by smoking status (non-smokers compared with smokers and non-smokers combined) in healthy individuals and individuals with renal or hepatic impairment

\begin{tabular}{|c|c|c|}
\hline & \multicolumn{2}{|c|}{ Median $\mathrm{AUC}_{\infty, \text { norm }}(\mathrm{kg} \cdot \mathrm{h} / \mathrm{L})$} \\
\hline & Non-smokers & Smokers and non-smokers \\
\hline \multicolumn{3}{|l|}{ Renal impairment study [33] } \\
\hline Normal ( $\mathrm{CrCl}>80$ mL/min $)$ & 22.0 & 21.4 \\
\hline Mild impairment ( $\mathrm{CrCl} 50-80 \mathrm{~mL} / \mathrm{min})$ & 40.4 & 33.9 \\
\hline Moderate impairment $(\mathrm{CrCl} 30-49 \mathrm{~mL} / \mathrm{min})$ & 65.2 & 40.9 \\
\hline Severe impairment $(\mathrm{CrCl}<30 \mathrm{~mL} / \mathrm{min})$ & 40.4 & 33.6 \\
\hline \multicolumn{3}{|l|}{ Hepatic impairment study [32] } \\
\hline Mild impairment (Child-Pugh A) & 43.3 & 32.7 \\
\hline Control A & 30.2 & 30.2 \\
\hline Moderate impairment (Child-Pugh B) & 39.4 & 36.3 \\
\hline Control B & 31.5 & 30.5 \\
\hline
\end{tabular}

$A U C_{\infty, \text { norm }}$ area under the plasma concentration-time curve from time zero to infinity divided by dose per kilogram body weight, $\mathrm{CrCl}$ creatinine clearance
In the mechanistic population pharmacokinetic model described in Sect. 4.3.1, hepatic impairment had a limited effect on total riociguat exposure and no significant effect on riociguat or M1 clearance.

\subsection{Age}

Riociguat half-life was prolonged by $+41 \%$ and riociguat renal clearance was decreased by $-28 \%$ in healthy elderly individuals (aged 64.5-80 years) compared with healthy young individuals (aged 18-45 years) [32]. Renal clearance showed a $28 \%$ reduction in elderly versus young individuals, as determined by direct assessment of renal clearance. The elderly had $+40 \%$ higher riociguat exposure (AUC) than the young (Table 1) but this difference was not statistically significant and was reduced to $+28 \%$ when exposure was normalized to body weight. M1 showed less pronounced differences between the elderly and the young than riociguat. Despite the pharmacokinetic differences, riociguat was well tolerated with a comparable safety profile in both age groups [32]. On population pharmacokinetic analysis, age itself was not a significant covariate for riociguat clearance, but was strongly correlated with $\mathrm{CrCl}$, which was a significant covariate [34].

\subsection{Sex}

In healthy volunteers who received a single 1 or $2.5 \mathrm{mg}$ dose, riociguat $C_{\max }$ was +32 and $+35 \%$ higher, respectively, in women than in men [32]. The difference became smaller when riociguat $C_{\max }$ was adjusted for body weight (approximately $+20 \%$ ), but remained significant. However, riociguat AUC showed no significant difference between women and men [30, 32]. M1 pharmacokinetics showed a similar pattern [32].

\section{Pharmacokinetic Properties in Patients with Pulmonary Arterial Hypertension and Chronic Thromboembolic Pulmonary Hypertension}

Key assessments of riociguat pharmacokinetics were performed in patients with PAH or CTEPH in a phase II, proof-of-concept, single-dose study [35], a phase II, openlabel, multiple-dose study (ClinicalTrials.gov identifier: NCT00454558) [15], and a population pharmacokinetic analysis of patients in the PATENT and CHEST studies [36]. As in healthy individuals, riociguat is rapidly absorbed in patients with PAH or CTEPH (time to reach $C_{\max }$ after a single dose $0.25-1.5 \mathrm{~h}$ ) [35]. Riociguat exposure is dose proportional, with pronounced interindividual variability $(60 \%)$ but low intraindividual variability $(35 \%)$ [15]. The half-life of riociguat is approximately $12 \mathrm{~h}$ in patients compared with approximately $7 \mathrm{~h}$ in healthy individuals $[18,19]$. The resulting exposure is approximately two- to threefold higher at steady state compared with healthy subjects [13]. Mean $\mathrm{AUC}_{\infty}$ after single doses of 1 and $2.5 \mathrm{mg}$ in the proof-of-concept study was 602 and $1411 \mu \mathrm{g} \cdot \mathrm{h} / \mathrm{L}$, respectively [35]. Mean AUC under steadystate conditions following multiple doses of riociguat 0.5-2.5 mg three times daily in the pivotal phase III trials was $1174 \mu \mathrm{g} \cdot \mathrm{h} / \mathrm{L}$ in patients with PAH and $1433 \mu \mathrm{g} \cdot \mathrm{h} / \mathrm{L}$ in patients with CTEPH (Table 3) [15]. Based on investigations early in the clinical trial program, riociguat accumulation up to steady state is anticipated within the first few days of administration (unpublished data). No undue accumulation beyond steady state was observed; exposure in the phase III trials remained stable from day 14 to day 168 [37]. In the phase III trials, riociguat/M1 plasma concentrations were well described by a linear one-compartment model, with no evidence for time- or dose- 
Table 3 Riociguat exposure data at steady state following multiple doses (individual dose adjustment up to $2.5 \mathrm{mg}$ three times daily) of riociguat in PATENT-1 and CHEST-1

\begin{tabular}{lll}
\hline Riociguat pharmacokinetic parameter & $\begin{array}{l}\text { Patients with PAH: PATENT-1 } \\
\text { study }(n=228)\end{array}$ & $\begin{array}{l}\text { Patients with CTEPH: CHEST-1 } \\
\text { study }(n=153)\end{array}$ \\
\hline $\mathrm{AUC}_{\mathrm{T}}(\mu \mathrm{g} \cdot \mathrm{h} / \mathrm{L})$ & & $1433(45.2)$ \\
Geometric mean $(\mathrm{CV})$ & $1174(55.0)$ & 1475 \\
Median & 1226 & $207(38.9)$ \\
$C_{\max }(\mu \mathrm{g} / \mathrm{L})$ & $176(47.8)$ & 213 \\
Geometric mean $(\mathrm{CV})$ & 178 & $145(58.4)$ \\
Median & $113(69.6)$ & 152 \\
$C_{\text {trough }}(\mu \mathrm{g} / \mathrm{L})$ & 124 & 152 \\
Geometric mean $(\mathrm{CV})$ & \\
Median & & \\
\hline
\end{tabular}

$A U C_{T}$ area under the plasma concentration-time curve at steady state, $C_{\text {max }}$ maximum concentration in plasma, $C T E P H$ chronic thromboembolic pulmonary hypertension, $C_{\text {trough }}$ minimum concentration in plasma, $C V$ coefficient of variation, $P A H$ pulmonary arterial hypertension

dependent alterations [36]. The absorption rate constant, clearance, and volume of distribution for riociguat were estimated to be $2.17 / \mathrm{h}, 1.81 \mathrm{~L} / \mathrm{h}$, and $32.3 \mathrm{~L}$, respectively [36]. Covariate effects in the model included smoking status, comedication with the endothelin receptor antagonist bosentan, bilirubin concentration, and baseline $\mathrm{CrCl}$. Smokers had higher riociguat clearance than non-smokers; in patients not receiving bosentan, taking into account other covariate effects (bilirubin concentration and $\mathrm{CrCl}$ ), median riociguat clearance was $1.8 \mathrm{~L} / \mathrm{h}$ in non-smokers and $4.2 \mathrm{~L} / \mathrm{h}$ in smokers in the PATENT studies, and $1.6 \mathrm{~L} /$ $\mathrm{h}$ in non-smokers and $4.2 \mathrm{~L} / \mathrm{h}$ in smokers in the CHEST studies. The final pharmacokinetic model in patients indicated that smoking was associated with a $120 \%$ increase in riociguat clearance [37]. Bosentan comedication was associated with a slight increase in riociguat clearance in the PATENT studies (described further in Sect. 7.1) [36]. Consistent with findings in healthy individuals, riociguat exposure showed a modest increase with age in patients with PAH or CTEPH in PATENT-1 and CHEST-1, respectively [32]. Riociguat AUC was approximately $10 \%$ higher in women than in men [32], and this modest difference may be partly due to differences in body weight between women and men.

\section{Pharmacodynamics and Pharmacokinetic/ Pharmacodynamic Relationships}

\subsection{Pharmacodynamics in Healthy Volunteers}

In healthy young volunteers, single doses of riociguat (1-5 mg) led to a dose-dependent increase in heart rate by 4-11 beats/min compared with placebo, reflecting a compensatory response to a vasodilating agent [27]. Heart rate correlated directly with riociguat plasma concentrations (Fig. 3). Mean arterial and diastolic blood pressure were slightly but significantly decreased following administration of riociguat 1 or $5 \mathrm{mg}$ compared with placebo, whereas SBP was not significantly affected, likely because of the compensatory increase in heart rate and presumably cardiac output. Orthostatic reactions were most common in the $5 \mathrm{mg}$ dose group, which was also the only dose group to show a significant increase in levels of norepinephrine compared with placebo. A significant, dose-dependent increase in plasma renin activity was observed after administration of riociguat $1-5 \mathrm{mg}$ but this was not accompanied by increases in plasma aldosterone or angiotensin II levels [27].

\subsection{Pharmacodynamics in Patients with Pulmonary Hypertension}

In patients with PAH or CTEPH, single doses of riociguat [1 mg $(n=5)$ or $2.5 \mathrm{mg}(n=10)]$ caused clinically relevant, statistically significant, concentration-dependent decreases from baseline in mean pulmonary arterial pressure, pulmonary vascular resistance (PVR), SBP, and systemic vascular resistance (SVR), as well as an increase in cardiac index [35]. Heart rate was significantly increased from baseline by riociguat $2.5 \mathrm{mg}$ but not $1 \mathrm{mg}$. Both doses of riociguat showed greater potency and duration of action than inhaled NO (10-20 ppm for $10 \mathrm{~min})$ in reducing PVR, SBP, and SVR, and increasing cardiac index. The $2.5 \mathrm{mg}$ dose of riociguat reduced mean pulmonary arterial pressure to a greater extent than NO. Riociguat did not worsen gas exchange or ventilation/perfusion matching despite causing strong pulmonary vasodilation [35]. 


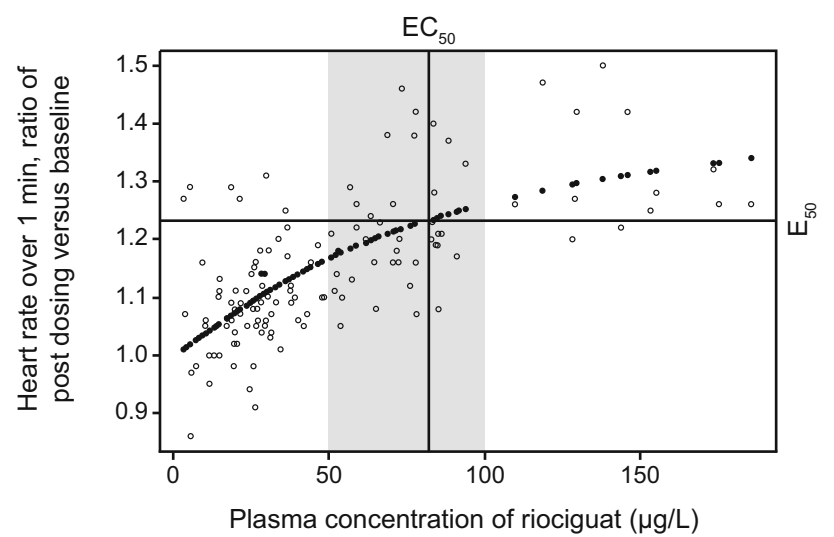

Fig. 3 Relationship between riociguat plasma concentration and heart rate over $1 \mathrm{~min}$, described using a sigmoid $E_{\max }$ model. Relative change in heart rate $=1+[(0.47 \times \mathrm{Cp}) /(82.3+\mathrm{Cp})]$. The shaded area represents the effective concentrations as characterized using the sigmoid $E_{\max }$ model. $C p$ riociguat plasma concentration, $E C_{50}$ half maximal effective concentration, $E_{50}$ half of $\mathrm{E}_{\max }, E_{\max }$ estimated maximal effect. Reproduced from Frey R, et al. J Clin Pharmacol. 2008;48(8):926-34, with permission. Copyright (c) 2008 John Wiley $\&$ Sons, Inc.

\subsection{Pharmacokinetic/Pharmacodynamic Relationships}

In an analysis of patients with PAH or CTEPH in the PATENT and CHEST studies, respectively, trough riociguat plasma concentrations were correlated with changes from baseline in hemodynamic parameters, including PVR, SBP, and cardiac output, demonstrating correspondence between exposure and hemodynamic response [36]. The change from baseline in 6MWD did not correlate directly with riociguat exposure (data not shown), but it did correlate with the changes in hemodynamic parameters, particularly PVR. The lack of direct correlation between riociguat exposure and 6MWD suggests that many different factors determine exercise capacity in patients with PAH or CTEPH [36]. The correlation between 6MWD and hemodynamic parameters suggests that an improvement in blood supply to skeletal muscles (possibly via an increase in cardiac output [38]) may contribute to the improvement in exercise capacity.

\section{Drug-Drug Interactions}

\subsection{Pharmacokinetic Interactions}

As riociguat solubility is influenced by $\mathrm{pH}$, drugs that alter gastric $\mathrm{pH}$ may affect riociguat absorption (Table 1). Cotreatment with an antacid $[10 \mathrm{~mL}$ of aluminum hydroxide/magnesium hydroxide $\left(\right.$ Maalox $\left.{ }^{\circledR}\right)$ ] reduced riociguat $C_{\max }$ and AUC by -56 and $-34 \%$, respectively [39]. Co- treatment with the proton pump inhibitor omeprazole $40 \mathrm{mg}$ once daily reduced riociguat $C_{\max }$ and AUC by -35 and $-26 \%$, respectively [39]. Co-treatment with the $\mathrm{H}_{2}$ antagonist ranitidine (150 $\mathrm{mg}$ once daily) reduced riociguat $C_{\max }$ by approximately $-15 \%$ and AUC by approximately $-10 \%$ [15].

Riociguat is a substrate of specific CYP proteins and the transporter proteins P-gp and BCRP [15, 18, 19]. Riociguat and $\mathrm{M} 1$ are neither inhibitors nor inducers of any major CYP isoforms in vitro at therapeutic concentrations, but they inhibit CYP1A1 (inhibition constant $0.6 \mu \mathrm{M}$ each) [15]. Therefore, clinically relevant interactions of riociguat with comedications that are significantly cleared via CYP1A1 (e.g. erlotinib or granisetron) cannot be ruled out.

Pre- and coadministration of clarithromycin $(500 \mathrm{mg}$ twice daily), a strong and selective CYP3A4 inhibitor and a weak-to-moderate P-gp inhibitor, moderately increased riociguat AUC by $+41 \%$ (Table 1) without a significant change in $C_{\max }$ [31]. Metabolite M1 AUC increased by $+19 \%$, again with no significant change in $C_{\max }$. Pre- and coadministration of the strong CYP3A4 and P-gp inhibitor ketoconazole (400 $\mathrm{mg}$ once daily) increased riociguat $C_{\max }$, and AUC increased by approximately +46 and $+150 \%$, respectively (Table 1) [31]. Riociguat half-life increased from 7.4 to $9.2 \mathrm{~h}$, and $\mathrm{CL} / \mathrm{F}$ of riociguat decreased from 6.1 to $2.4 \mathrm{~L} / \mathrm{h}$. Metabolite M1 $C_{\max }$ and AUC decreased by approximately -49 and $-24 \%$, respectively, and M1 half-life increased from 16.2 to $18.3 \mathrm{~h} \mathrm{[31].}$

The sensitive CYP3A4 substrate midazolam $(7.5 \mathrm{mg})$ showed no significant interaction with riociguat pre- and co-treatment, confirming that riociguat does not influence the metabolism of other drugs via CYP3A4 [31].

Female patients with PAH are advised to avoid pregnancy [1], and oral contraception is the main method used [40]. The interaction of riociguat with levonorgestrel $(0.15 \mathrm{mg})$ and ethinylestradiol $(0.03 \mathrm{mg})$ in a combined oral contraceptive was therefore assessed. Riociguat preand co-treatment did not alter the AUC of levonorgestrel or ethinylestradiol, or the $C_{\max }$ of levonorgestrel; the $C_{\max }$ of ethinylestradiol was increased by $+20 \%$ but this was not expected to have an adverse impact on the efficacy of the contraceptive. Riociguat exposure was not influenced by coadministration of levonorgestrel-ethinylestradiol [40].

Bosentan is a PAH-targeted therapy that induces CYP3A4 and may be coadministered with riociguat [41]. Bosentan was associated with a moderate decrease in riociguat AUC $(-27 \%)$ in patients with PAH and CTEPH in the PATENT and CHEST studies (Table 1) [37]. This effect was not considered sufficient to necessitate dose adjustment of riociguat $[19,42]$. Riociguat and the PAHspecific therapy sildenafil [a phosphodiesterase-5 (PDE-5) inhibitor] showed no mutual pharmacokinetic interaction 
in vivo, but an additive hemodynamic effect was observed in a small interaction study (NCT00680654) [15, 18, 19] and potentially unfavorable safety signals were observed in a long-term study of the combination of riociguat with sildenafil (PATENT PLUS) [43] (see Sect. 7.2).

No clinically relevant drug-drug interactions due to inhibition of transporters such as P-gp or BCRP, or organic anion transporting polypeptides OATP1B1 and OATP1B3, organic anion transporters OAT1 and OAT3, or organic cation transporters (OCTs) by riociguat are expected [15]. Furthermore, metabolite M1 (BAY 60-4552) is not an inhibitor of $\mathrm{P}-\mathrm{gp}, \mathrm{BCRP}$, or OCTs at relevant therapeutic concentrations [15].

All clinically relevant interactions are described in the product labels [19].

\subsection{Pharmacodynamic Interactions}

As described in Sect. 2.2, sGC activity is increased to a greater extent by riociguat in combination with an NOreleasing drug than by riociguat alone [23]. Thus, riociguat and NO-releasing drugs may be expected to have an additive effect on the systemic circulation. In a phase I study in healthy volunteers, administration of sublingual nitroglycerin $0.4 \mathrm{mg} 4 \mathrm{~h}$ after a single dose of riociguat $2.5 \mathrm{mg}$ resulted in a pronounced pharmacodynamic interaction with significant hypotensive effects necessitating drug withdrawal (which could not be quantified because the study was terminated after only six patients had been enrolled) [15].

As riociguat and PDE-5 inhibitors, such as sildenafil, both act on the NO-sGC-cGMP pathway, with different targets/ mechanisms of action, they may be expected to have an additive or synergistic effect by increasing the intracellular cGMP concentration if used in combination. The addition of riociguat (up to $2.5 \mathrm{mg}$ three times daily) in patients with PAH receiving stable sildenafil therapy $(20 \mathrm{mg}$ three times daily) was evaluated in the small PATENT PLUS study ( $n=18$ ), which had a 12-week placebo-controlled phase followed by an uncontrolled long-term extension phase [43]. The addition of riociguat to sildenafil had no significant beneficial effect on WHO functional class, 6MWD, or hemodynamic parameters, including mean pulmonary arterial pressure, PVR, or cardiac index, in the placebo-controlled phase. Adverse events were reported by 12 patients receiving riociguat during the randomized phase; these were considered to be drug-related in seven patients. During the extension phase (mean total treatment duration 305 days), there were high rates of discontinuation due to hypotension (23.5\%; three adverse events and one serious adverse event, all considered related to study drug) and a mortality rate of $18 \%$ (3/17 patients); none of the deaths were considered to be drug-related. For comparison, in PATENT-1, deaths related to adverse events occurred in two patients $(1 \%)$ in the $2.5 \mathrm{mg}$-maximum group and in three patients $(2 \%)$ in the placebo group. None of the deaths were considered related to the study drug [13]. In PATENT-2, the estimated survival rate was $97 \%$ at 1 year [16]. In CHEST-1, deaths related to adverse events occurred in two patients $(1 \%)$ in the riociguat group and three patients (3\%) in the placebo group [12]. In CHEST-2, estimated overall survival at 1 year was $97 \%$ [17].

Thrombosis contributes to the pulmonary arteriopathy that is present in CTEPH and PAH [44, 45], and long-term use of oral anticoagulants is recommended for patients with CTEPH and some patients with PAH [1, 46]. Riociguat is thus likely to be coadministered with warfarin [47]. Therefore, potential interactions between riociguat and warfarin were investigated in healthy volunteers. Pre- and coadministration of riociguat $2.5 \mathrm{mg}$ three times daily did not influence warfarin pharmacodynamics: the $90 \%$ confidence interval (CI) for the ratio (warfarin + riociguat)/ (warfarin + placebo) was 0.97-1.01 for prothrombin time $\mathrm{AUC}_{96 \mathrm{~h}}$ and 1.00-1.06 for factor VII percentage activity $\mathrm{AUC}_{96 \mathrm{~h}}$. Warfarin and riociguat showed no clinically relevant mutual pharmacokinetic interactions [48].

In patients with $\mathrm{PAH}$, acetylsalicylic acid might be administered at a low dose for anticoagulant activity, or at a high dose for pain relief. The potential of riociguat to increase the anti-aggregatory effect of acetylsalicylic acid was therefore evaluated [49]. In healthy individuals, the effects of acetylsalicylic acid $500 \mathrm{mg}$ on bleeding time, platelet aggregation, and serum thromboxane $B_{2}$ levels were not influenced by coadministration of riociguat $2.5 \mathrm{mg}$. Thus, no clinically relevant pharmacodynamic interaction between riociguat and acetylsalicylic acid was detected [49].

\section{Discussion}

The pharmacokinetic and pharmacodynamic data for riociguat have been used to guide its clinical use in patients with PAH and CTEPH. The pharmacokinetics of riociguat have been extensively characterized in phase I and II studies and in population pharmacokinetic modeling analyses. Based on data from pharmacokinetic studies, riociguat shows complete oral absorption with doseproportional exposure over the therapeutic dose range $(0.5-2.5 \mathrm{mg})$ and can be taken with or without food [18, 19, 28, 30]. Crushed tablets and oral suspensions of riociguat are interchangeable with whole tablets [30]. This may be useful in populations who have difficulty swallowing whole tablets.

Population pharmacokinetic analyses confirm that riociguat pharmacokinetics are described by a one- 
compartment model in patients with PAH or CTEPH and are similar in the two conditions, but exposure is increased compared with healthy individuals $[32,33]$. While some of the expected intrinsic factors, such as age (with reductions in renal excretion and/or hepatobiliary clearance), may contribute in part to this increase in exposure, the underlying disease per se alters renal and/or hepatobiliary elimination of drugs owing to various factors, including reduced cardiac output, liver shunts, and worsening renal function [50-54]. Accordingly, patient covariates such as renal function and bilirubin reduced unexplained interindividual variability of systemic clearance in patients with PAH or CTEPH described via population pharmacokinetic approaches [34, 37]. In the population pharmacokinetic analyses, only renal function appeared to be a significant covariate affecting exposure [37]. Of note, median $\mathrm{CrCl}$ levels at baseline in the PATENT and CHEST studies were 86.6 and $72.8 \mathrm{~mL} / \mathrm{min}$, respectively, suggesting a degree of renal impairment [37]. Mean cardiac index at baseline in the CHEST study population was 2.2-2.3 L/min $/ \mathrm{m}^{2}$, suggesting impaired cardiac function [38].

Differences in riociguat exposure due to age or sex are not clinically relevant and do not warrant further dose adjustment beyond the approved individual dose-adjustment scheme [30, 32, 40]. However, particular care should be exercised during individual dose adjustment in elderly patients because riociguat exposure tends to be somewhat higher in older versus younger individuals, partly due to differences in body weight and renal clearance [19, 32].

Renal impairment is associated with reduced riociguat clearance. Dose adjustment of riociguat should be performed with particular care in patients with renal impairment $[19,30,33]$. Data are limited for patients with severe renal impairment $(\mathrm{CrCl}<30 \mathrm{~mL} / \mathrm{min})$ and riociguat is therefore not recommended for these patients in the European label [19], although this restriction is not applied in the US label [18]. No data are available for patients with $\mathrm{CrCl}<15 \mathrm{~mL} / \mathrm{min}$ or on dialysis, and riociguat is therefore not recommended in these patients in both the European and US labels [18, 19].

Dose adjustment of riociguat should be performed with particular care in patients with moderate hepatic impairment (Child-Pugh B) because drug exposure is increased [32]. Mild hepatic impairment (Child-Pugh A) is not associated with significant alteration of riociguat exposure [32]. There is no experience in patients with severe hepatic impairment (Child-Pugh C); for these patients, riociguat is contraindicated in the European label [19] and is not recommended in the US label [18].

Smoking is one of the main factors contributing to the variability of riociguat exposure; quantitative variations in smoking habits or other environmental or dietary factors that induce CYP1A1 (e.g. consumption of cruciferous vegetables or charcoal-broiled meat $[55,56])$ may contribute to interindividual variability in the separate subpopulations of smokers and non-smokers [15]. However, there is no reason to suspect that these factors differed substantially between smokers and non-smokers in the riociguat studies, and the effect of smoking on riociguat exposure has been observed in studies controlled for diet and environment [29]. CYP induction by smoking is dosedependent [57] and a dedicated analysis of the phase II and III studies of riociguat suggested such a relationship; however, the number of patients was too small to permit firm conclusions (unpublished data). The European label advises that dose adjustments may be necessary in patients who start or stop smoking during riociguat treatment [19], while the US label notes that patients who smoke may require riociguat dosages higher than $2.5 \mathrm{mg}$ three times daily if tolerated, and that a dose decrease may be required in patients who stop smoking [18].

To reduce the risk of hypotension, the use of riociguat in patients with $\mathrm{SBP}<95 \mathrm{mmHg}$ at treatment initiation is contraindicated in the European label [19]. During riociguat therapy, $\mathrm{SBP}<95 \mathrm{mmHg}$ is not a contraindication, although dose reduction is recommended if SBP below this level is accompanied by signs or symptoms of hypotension [19]. The US label does not have a contraindication based on SBP, but a dose reduction is recommended if the patient has symptoms of hypotension. Uptitration to a maximum dose of $2.5 \mathrm{mg}$ three times daily is recommended if SBP remains $>95 \mathrm{mmHg}$ and the patient has no signs or symptoms of hypotension [18].

The pharmacodynamic effects of riociguat on systemic and pulmonary circulation correlated with riociguat plasma concentrations [27, 35, 36], which showed moderate to high interindividual variability [27, 28]. The riociguat individual dose-adjustment scheme, including the threetimes-daily dosing (Fig. S1 in the Online Resource) was developed in part to manage this variability and the individual sensitivity to riociguat exposure, and is based on data from phase I and II studies; the rationale, development, and implementation of the scheme have been described elsewhere $[13,14]$. Briefly, riociguat doses are adjusted at 2-week intervals according to SBP (which correlates with riociguat plasma concentrations in patients with PAH or CTEPH [35, 36]) and signs/symptoms of hypotension [18, 19]. The 2-week interval was chosen based on the time taken to reach hemodynamic steady state, and convenience for the patient [14]. This approach allows for adjustment to the highest tolerated riociguat dose for each patient, has been proven in phase III clinical studies, and appears to be practical and straightforward in clinical practice. Three-times-daily dosing would be expected to provide a flat plasma concentration-time 
profile, which could be beneficial for an agent with hemodynamic effects. Intraindividual variability in riociguat plasma concentrations is low, suggesting that exposure should remain consistent over time once the appropriate dose for an individual patient has been established [15]. In support of this, the maintenance dose of riociguat was not changed in the majority of patients during the open-label phases of the long-term extension trials PATENT-2 and CHEST-2 [16, 17].

Riociguat has a low risk of clinically relevant drug interactions due to its clearance and excretion by multiple CYP and transporter enzymes and its lack of effect on major CYP isoforms at therapeutic levels [15]. However, absorption is affected by gastric $\mathrm{pH}$, and antacids should not be administered within $1 \mathrm{~h}$ of receiving riociguat according to the US label [18]. The European label advises that antacids should be taken at least $2 \mathrm{~h}$ before or $1 \mathrm{~h}$ after riociguat [19]. Proton pump inhibitors and $\mathrm{H}_{2}$ antagonists also affect riociguat bioavailability, but to a lesser extent than antacids [15]; the use of proton pump inhibitors or $\mathrm{H}_{2}$ antagonists does not require adaptation of dosing beyond the individual dose-adjustment scheme. The same is true for coadministration of riociguat with strong selective CYP3A4 inhibitors, combined oral contraceptives [40], acetylsalicylic acid [49], or warfarin [18, 19, 48]. By contrast, the PDE-5 inhibitors sildenafil and tadalafil are metabolized predominantly by CYP3A, and concomitant use of strong CYP3A inhibitors is not recommended or requires dose reductions [58-61].

Although coadministration of riociguat with selective CYP3A4 inhibitors does not require additional dose adaptation [31], concomitant use with strong multipathway CYP and P-gp/BCRP inhibitors, such as ketoconazole and HIV protease inhibitors, should be approached with caution as there is a risk of hypotension, as explained above [19, 31]; the US label recommends considering a reduced riociguat starting dose of $0.5 \mathrm{mg}$ three times daily in this context [18]. Evaluation of data from a recently completed, non-randomized, open-label, parallel-group study exploring the concomitant use of riociguat and HIV protease inhibitors in the most widely used antiretroviral combinations is ongoing (NCT02556268; $n=40$ ). This trial was based on in vitro studies of interactions between riociguat and anti-HIV drugs (unpublished data). The aims of the study were to investigate the pharmacokinetic drug-drug interaction potential between riociguat and fixed-dose HIV antiretroviral therapies $\left(\right.$ Atripla $^{\circledR}{ }^{\circledR}$ Complera $^{\circledR}$, Stribild $^{\circledR}$, or Triumeq ${ }^{\circledR}$ ) or any approved antiretroviral protease inhibitor in combination with (preferably) Triumeq ${ }^{\circledR}$, and to assess the safety and tolerability of riociguat treatment in combination with these therapies. The potential importance of such studies is illustrated by the increased risk of developing PAH in patients with HIV [62] and the recognition of PAH associated with HIV in the international classification of $\mathrm{PH}$ [3].

Because of its low potential for drug-drug interactions, riociguat can be used in combination with endothelin receptor antagonists and/or prostanoids, as confirmed in the PATENT study $[13,16]$. In contrast to riociguat, bosentan is an inducer of CYP3A4 and CYP2C9 and therefore interacts with multiple other drugs [63, 64]. Coadministration of riociguat with bosentan is associated with increased clearance and reduced plasma concentrations of riociguat, but does not necessitate any changes in treatment beyond the individual dose-adjustment scheme $[19,30]$.

Coadministration of riociguat with nitrates or NO donors is contraindicated in the European and US labels because of the risk of developing hypotension $[15,18,19]$. Coadministration of riociguat with PDE-5 inhibitors is also contraindicated $[18,19]$, based on the unfavorable safety signals and lack of favorable clinical effect observed following addition of riociguat to sildenafil in the PATENT PLUS study [43].

However, it is possible that patients who are not achieving treatment goals on a PDE-5 inhibitor may benefit from switching to riociguat, as suggested by data from the RESPITE study [65]. This is consistent with the modes of action of riociguat and PDE-5 inhibitors: riociguat can stimulate sGC independently of NO, while sensitizing sGC to low levels of NO, whereas PDE-5 inhibitors (which prevent degradation of cGMP) depend on the presence of sufficient upstream NO and may therefore be limited by the NO deficiency found in PH [6]. In cases of switching from a PDE-5 inhibitor to riociguat (and vice versa), the transition must include a washout phase to avoid an overlap in exposure. Based on the half-lives of the respective drugs, riociguat should not be administered within $24 \mathrm{~h}$ of receiving sildenafil, or within $24 \mathrm{~h}$ before or $48 \mathrm{~h}$ after receiving tadalafil, as described in the US label [18].

\section{Conclusions}

The pharmacodynamic and pharmacokinetic properties of riociguat have been comprehensively evaluated in healthy individuals and patients with $\mathrm{PH}$. These properties support the individual dose-adjustment scheme used in phase II and III clinical trials of riociguat and are reflected in the prescribing information for riociguat [18]. The novel mode of action of riociguat, its individualized dose-adjustment regimen, and its low risk of drug-drug interactions support its uptake in the pharmacologic treatment of PAH and as the only approved pharmacotherapy for inoperable or persistent/recurrent CTEPH. 
Acknowledgements Medical writing assistance was provided by Adelphi Communications Ltd, funded by Bayer AG.

\section{Compliance with Ethical Standards}

Funding Support for the preparation of this manuscript was provided by Bayer AG.

Conflict of interest Reiner Frey is a former employee of, and now a consultant to, Bayer AG. Corina Becker, Soundos Saleh, Sigrun Unger, Dorina van der Mey, and Wolfgang Mück are employees of Bayer AG. Reiner Frey, Sigrun Unger, and Wolfgang Mück own stock in Bayer.

Open Access This article is distributed under the terms of the Creative Commons Attribution-NonCommercial 4.0 International License (http://creativecommons.org/licenses/by-nc/4.0/), which permits any noncommercial use, distribution, and reproduction in any medium, provided you give appropriate credit to the original author(s) and the source, provide a link to the Creative Commons license, and indicate if changes were made.

\section{References}

1. Galiè N, Humbert M, Vachiery JL, Gibbs S, Lang I, Torbicki A, et al. 2015 ESC/ERS Guidelines for the diagnosis and treatment of pulmonary hypertension: The joint task force for the diagnosis and treatment of pulmonary hypertension of the European Society of Cardiology (ESC) and the European Respiratory Society (ERS): Endorsed by: Association for European Paediatric and Congenital Cardiology (AEPC), International Society for Heart and Lung Transplantation (ISHLT). Eur Respir J. 2015;46(4):903-75.

2. Tuder RM, Archer SL, Dorfmuller P, Erzurum SC, Guignabert C, Michelakis E, et al. Relevant issues in the pathology and pathobiology of pulmonary hypertension. J Am Coll Cardiol. 2013;62(25 Suppl):D4-12.

3. Simonneau G, Gatzoulis MA, Adatia I, Celermajer D, Denton C, Ghofrani A, et al. Updated clinical classification of pulmonary hypertension. J Am Coll Cardiol. 2013;62(25 Suppl):D34-41.

4. McLaughlin VV, McGoon MD. Pulmonary arterial hypertension. Circulation. 2006;114(13):1417-31.

5. Ghofrani HA, Humbert M, Langleben D, Schermuly R, Stasch JP, Wilkins MR, et al. Riociguat: mode of action and clinical development in pulmonary hypertension. Chest. 2017;151(2):468-80.

6. Stasch JP, Evgenov OV. Soluble guanylate cyclase stimulators in pulmonary hypertension. Handb Exp Pharmacol. 2013;218:279-313.

7. Stasch JP, Pacher P, Evgenov OV. Soluble guanylate cyclase as an emerging therapeutic target in cardiopulmonary disease. Circulation. 2011;123(20):2263-73.

8. Hoeper MM, Halank M, Wilkens H, Gunther A, Weimann G, Gebert I, et al. Riociguat for interstitial lung disease and pulmonary hypertension: a pilot trial. Eur Respir J. 2013;41(4):853-60.

9. Ghofrani HA, Staehler G, Grunig E, Halank M, Mitrovic V, Unger $\mathrm{S}$, et al. Acute effects of riociguat in borderline or manifest pulmonary hypertension associated with chronic obstructive pulmonary disease. Pulm Circ. 2015;5:296-304.

10. Bonderman D, Ghio S, Felix SB, Ghofrani HA, Michelakis ED, Mitrovic V, et al. Riociguat for patients with pulmonary hypertension due to systolic left ventricular dysfunction: a phase IIb double-blind, randomized, placebo-controlled, dose-ranging hemodynamic study. Circulation. 2013;128(5):502-11.

11. Bonderman D, Pretsch I, Steringer-Mascherbauer R, Jansa P, Rosenkranz S, Tufaro C, et al. Acute hemodynamic effects of riociguat in patients with pulmonary hypertension associated with diastolic heart failure (DILATE-1): a randomized, double-blind, placebo-controlled, single-dose study. Chest. 2014;146(5): 1274-85.

12. Ghofrani HA, D’Armini AM, Grimminger F, Hoeper MM, Jansa $\mathrm{P}$, Kim NH, et al. Riociguat for the treatment of chronic thromboembolic pulmonary hypertension. $N$ Engl $J$ Med. 2013;369(4):319-29.

13. Ghofrani HA, Galiè N, Grimminger F, Grunig E, Humbert M, Jing ZC, et al. Riociguat for the treatment of pulmonary arterial hypertension. N Engl J Med. 2013;369(4):330-40.

14. Hill NS, Rahaghi FF, Sood N, Frey R, Ghofrani HA. Individual dose adjustment of riociguat in patients with pulmonary arterial hypertension and chronic thromboembolic pulmonary hypertension. Respir Med. 2017;129:124-9.

15. Bayer Healthcare Pharmaceuticals, Inc. Briefing Document for Cardiovascular and Renal Drugs Advisory Committee: Riociguat (BAY 63-2521) 2013. https://wayback.archive-it.org/7993/201704 05211652/https://www.fda.gov/downloads/AdvisoryCommittees/ CommitteesMeetingMaterials/Drugs/CardiovascularandRenalD rugsAdvisoryCommittee/UCM363543.pdf.

16. Ghofrani HA, Grimminger F, Grunig E, Huang Y, Jansa P, Jing $\mathrm{ZC}$, et al. Predictors of long-term outcomes in patients treated with riociguat for pulmonary arterial hypertension: data from the PATENT-2 open-label, randomised, long-term extension trial. Lancet Respir Med. 2016;4:361-71.

17. Simonneau G, D’Armini AM, Ghofrani HA, Grimminger F, Jansa $\mathrm{P}, \mathrm{Kim} \mathrm{NH}$, et al. Predictors of long-term outcomes in patients treated with riociguat for chronic thromboembolic pulmonary hypertension: data from the CHEST-2 open-label, randomised, long-term extension trial. Lancet Respir Med. 2016;4(5):372-80.

18. Bayer A.G. Adempas, US prescribing information 2017. http:// labeling.bayerhealthcare.com/html/products/pi/Adempas_PI.pdf.

19. Bayer A.G. Adempas (riociguat tablets): EU summary of product characteristics. http://www.emaeuropaeu/docs/en_GB/document_ library/EPAR_-_Product_Information/human/002737/WC500165 034pdf. 2017.

20. Rubin LJ, Galiè N, Grimminger F, Grunig E, Humbert M, Jing $\mathrm{ZC}$, et al. Riociguat for the treatment of pulmonary arterial hypertension: a long-term extension study (PATENT-2). Eur Respir J. 2015;45(5):1303-13.

21. Simonneau G, D'Armini AM, Ghofrani HA, Grimminger F, Hoeper MM, Jansa P, et al. Riociguat for the treatment of chronic thromboembolic pulmonary hypertension: a long-term extension study (CHEST-2). Eur Respir J. 2015;45(5):1293-302.

22. US Food and Drug Administration, Center for Drug Evaluation and Research. Riociguat clinical pharmacology and biopharmaceutics review. http://www.accessdatafdagov/drugsatfda_docs/ nda/2013/204819Orig1s000ClinPharmRpdf. 2013.

23. Schermuly RT, Stasch JP, Pullamsetti SS, Middendorff R, Muller $\mathrm{D}$, Schluter KD, et al. Expression and function of soluble guanylate cyclase in pulmonary arterial hypertension. Eur Respir J. 2008;32(4):881-91.

24. Stasch JP, Hobbs AJ. NO-independent, haem-dependent soluble guanylate cyclase stimulators. Handb Exp Pharmacol. 2009;191:277-308.

25. Follmann M, Griebenow N, Hahn MG, Hartung I, Mais FJ, Mittendorf $J$, et al. The chemistry and biology of soluble guanylate cyclase stimulators and activators. Angew Chem Int Ed Engl. 2013;52(36):9442-62.

26. Sharkovska Y, Kalk P, Lawrenz B, Godes M, Hoffmann LS, Wellkisch K, et al. Nitric oxide-independent stimulation of 
soluble guanylate cyclase reduces organ damage in experimental low-renin and high-renin models. J Hypertens. 2010;28(8): 1666-75.

27. Frey R, Muck W, Unger S, Artmeier-Brandt U, Weimann G, Wensing G. Single-dose pharmacokinetics, pharmacodynamics, tolerability, and safety of the soluble guanylate cyclase stimulator BAY 63-2521: an ascending-dose study in healthy male volunteers. J Clin Pharmacol. 2008;48(8):926-34.

28. Becker C, Frey R, Hesse C, Unger S, Reber M, Muck W. Absorption of riociguat (BAY 63-2521): bioavailability, food effects, and dose proportionality. Pulm Circ. 2016;6(Suppl 1): S27-34

29. Zhao X, Wang Z, Wang Y, Zhang H, Blode H, Yoshikawa K, et al. Pharmacokinetics of the soluble guanylate cyclase stimulator riociguat in healthy young chinese male non-smokers and smokers: results of a randomized, double-blind, placebo-controlled study. Clin Pharmacokinet. 2016;55(5):615-24.

30. Saleh S, Frey R, Becker C, Unger S, Wensing G, Mück W. Bioavailability, pharmacokinetics, and safety of riociguat given as an oral suspension or crushed tablet with and without food. Pulm Circ. 2016;6(Suppl 1):S66-74.

31. Becker C, Frey R, Unger S, Thomas D, Reber M, Weimann G, et al. Pharmacokinetic interaction of riociguat with ketoconazole, clarithromycin, and midazolam. Pulm Circ. 2016;6(Suppl 1): S49-57.

32. Frey R, Becker C, Unger S, Schmidt A, Wensing G, Muck W. Assessment of the effects of hepatic impairment and smoking on the pharmacokinetics of a single oral dose of the soluble guanylate cyclase stimulator riociguat (BAY 63-2521). Pulm Circ. 2016;6(Suppl 1):S5-14.

33. Frey R, Becker C, Unger S, Schmidt A, Wensing G, Muck W. Assessment of the effects of renal impairment and smoking on the pharmacokinetics of a single oral dose of the soluble guanylate cyclase stimulator riociguat (BAY 63-2521). Pulm Circ. 2016;6(Suppl 1):S15-26.

34. Frey R, Saleh S, Becker C, Muck W. Effects of age and sex on the pharmacokinetics of the soluble guanylate cyclase stimulator riociguat (BAY 63-2521). Pulm Circ. 2016;6(Suppl 1):S58-65.

35. Grimminger F, Weimann G, Frey R, Voswinckel R, Thamm M, Bolkow D, et al. First acute haemodynamic study of soluble guanylate cyclase stimulator riociguat in pulmonary hypertension. Eur Respir J. 2009;33(4):785-92.

36. Saleh S, Becker C, Frey R, Muck W. Population pharmacokinetics of single-dose riociguat in patients with renal or hepatic impairment. Pulm Circ. 2016;6(Suppl 1):S75-85.

37. Saleh S, Becker C, Frey R, Muck W. Population pharmacokinetics and the pharmacokinetic/pharmacodynamic relationship of riociguat in patients with pulmonary arterial hypertension or chronic thromboembolic pulmonary hypertension. Pulm Circ. 2016;6(Suppl 1):S86-96.

38. Kim N, D’ Armini A, Grimminger F, Grunig E, Hoeper M, Jansa $\mathrm{P}$, et al. Haemodynamic effects of riociguat in inoperable/recurrent chronic thromboembolic pulmonary hypertension. Heart. 2017;103:599-606.

39. Becker C, Frey R, Unger S, Artmeier-Brandt U, Weimann G, Mück W. Effects of omeprazole and aluminum hydroxide/ magnesium hydroxide on riociguat absorption. Pulm Circ. 2016;6(Suppl 1):S43-8.

40. Frey R, Unger S, Van Der Mey D, Becker C, Saleh S, Wensing G. Pharmacokinetic interaction study between riociguat and the combined oral contraceptives levonorgestrel and ethinylestradiol in healthy postmenopausal women. Pulm Circ. 2016;6(Suppl 1): S97-102.

41. Dingemanse J, Schaarschmidt D, van Giersbergen P. Investigation of the mutual pharmacokinetic interactions between bosentan, a dual endothelin receptor antagonist, and simvastatin. Clinical Pharmacokinetics. 2003;42(3):293-301.

42. Bayer Healthcare Pharmaceuticals, Inc. FDA Draft Briefing Document for the Cardiovascular and Renal Drugs Advisory Committee (CRDAC) 2013 [1-315]. https://wayback.archiveit.org/7993/20170405211627/https://www.fda.gov/downloads/ AdvisoryCommittees/CommitteesMeetingMaterials/Drugs/CardiovascularandRenalDrugsAdvisoryCommittee/ UCM363541.pdf.

43. Galiè N, Muller K, Scalise AV, Grunig E. PATENT PLUS: a blinded, randomised and extension study of riociguat plus sildenafil in PAH. Eur Respir J. 2015;45(5):1314-22.

44. Johnson SR, Granton JT, Mehta S. Thrombotic arteriopathy and anticoagulation in pulmonary hypertension. Chest. 2006;130(2):545-52.

45. Lang IM, Pesavento R, Bonderman D, Yuan JX. Risk factors and basic mechanisms of chronic thromboembolic pulmonary hypertension: a current understanding. Eur Respir J. 2013;41(2):462-8.

46. McLaughlin VV, Archer SL, Badesch DB, Barst RJ, Farber HW, Lindner JR, et al. ACCF/AHA 2009 expert consensus document on pulmonary hypertension a report of the American College of Cardiology Foundation Task Force on Expert Consensus Documents and the American Heart Association developed in collaboration with the American College of Chest Physicians; American Thoracic Society, Inc.; and the Pulmonary Hypertension Association. J Am Coll Cardiol. 2009;53(17):1573-619.

47. Kim MJ, Huang SM, Meyer UA, Rahman A, Lesko LJ. A regulatory science perspective on warfarin therapy: a pharmacogenetic opportunity. J Clin Pharmacol. 2009;49(2):138-46.

48. Frey R, Mück W, Kirschbaum N, Kratzschmar J, Weimann G, Wensing G. Riociguat (BAY 63-2521) and warfarin: a pharmacodynamic and pharmacokinetic interaction study. J Clin Pharmacol. 2011;51(7):1051-60.

49. Frey R, Reber M, Kratzschmar J, Unger S, Mück W, Wensing G. Riociguat (BAY 63-2521) and aspirin: a randomized, pharmacodynamic, and pharmacokinetic interaction study. Pulm Circ. 2016;6(Suppl 1):S35-42.

50. Shammas F, Dickstein K. Clinical pharmacokinetics in heart failure. An updated review. Clin Pharmacokinet. 1988;15(2):97-113.

51. Williams RL, Benet LZ. Drug pharmacokinetics in cardiac and hepatic disease. Annu Rev Pharmacol Toxicol. 1980;20:389-413.

52. Ng CY, Ghabrial H, Morgan DJ, Ching MS, Smallwood RA, Angus PW. Right heart failure impairs hepatic elimination of $p$ nitrophenol without inducing changes in content or latency of hepatic UDP-glucuronosyltransferases. J Pharmacol Exp Ther. 2000;295(2):830-5.

53. Ng CY, Ghabrial H, Morgan DJ, Ching MS, Smallwood RA, Angus PW. Impaired elimination of propranolol due to right heart failure: drug clearance in the isolated liver and its relationship to intrinsic metabolic capacity. Drug Metab Dispos. 2000;28(10):1217-21.

54. Mielniczuk LM, Chandy G, Stewart D, Contreras-Dominguez V, Haddad H, Pugliese C, et al. Worsening renal function and prognosis in pulmonary hypertension patients hospitalized for right heart failure. Congest Heart Fail. 2012;18(3):151-7.

55. Hodges RE, Minich DM. Modulation of metabolic detoxification pathways using foods and food-derived components: a scientific review with clinical application. J Nutr Metab. 2015;2015:760689.

56. Conney AH, Reidenberg MM. Cigarette smoking, coffee drinking, and ingestion of charcoal-broiled beef as potential modifiers of drug therapy and confounders of clinical trials. J Pharmacol Exp Ther. 2012;342(1):9-14. 
57. Anttila S, Tuominen P, Hirvonen A, Nurminen M, Karjalainen A, Hankinson O, et al. CYP1A1 levels in lung tissue of tobacco smokers and polymorphisms of CYP1A1 and aromatic hydrocarbon receptor. Pharmacogenetics. 2001;11(6):501-9.

58. Eli-Lilly. Adcirca EU Summary of Product Characteristics 2013. http://www.ema.europa.eu/docs/en_GB/document_library/EPAR__Product_Information/human/001021/WC500032789.pdf.

59. Eli-Lilly. Adcirca prescribing information 2017. http://pi.lilly. com/us/adcirca-pi.pdf.

60. Pfizer. Revatio: EU Summary of Product Characteristics 2010. http://www.ema.europa.eu/docs/en_GB/document_library/EPAR__Product_Information/human/000638/WC500055840.pdf.

61. Pfizer. Revatio ${ }^{\circledR}$ : US prescribing information. 2014. http://www. accessdatafdagov/drugsatfda_docs/label/2014/021845s011,0224 73s004,0203109s002lblpdf.
62. Almodovar S, Cicalini S, Petrosillo N, Flores SC. Pulmonary hypertension associated with HIV infection: pulmonary vascular disease: the global perspective. Chest. 2010;137(6 Suppl):6S$12 \mathrm{~S}$.

63. Actelion. Summary of product characteristics: Tracleer 2016. http://www.ema.europa.eu/docs/en_GB/document_library/EPAR_-Product_Information/human/000401/WC500041597.pdf.

64. Dingemanse J, van Giersbergen P. Clinical pharmacology of bosentan, a dual endothelin receptor antagonist. Clin Pharmacokinet. 2004;43(15):1089-115.

65. Hoeper MM, Corris PA, Klinger J, Langleben D, Naeije R, Simonneau G, et al. The RESPITE Study: riociguat in patients with PAH and an inadequate response to phosphodiesterase 5 inhibitors. Am J Respir Crit Care Med. 2016;193:A6315. 